\title{
Child Pedestrian Safety: Study of Street-Crossing Behaviour of Primary School Children with Adult Supervision
}

\author{
Malik Sarmad Riaz ${ }^{1, *}$, Ariane Cuenen ${ }^{2}$, Evelien Polders ${ }^{2}$, Muhammad Bilal Akram ${ }^{2}{ }^{(}$, , Moustafa Houda ${ }^{3}(0$, \\ Davy Janssens ${ }^{2}$ and Marc Azab ${ }^{3}$ \\ 1 Civil Engineering Department-National University of Technology (NUTECH), Islamabad, Pakistan \\ 2 UHasselt-Hasselt University, Transportation Research Institute (IMOB), School of Transportation Sciences, \\ 3590 Diepenbeek, Belgium; ariane.cuenen@uhasselt.be (A.C.); evelien.polders@uhasselt.be (E.P.); \\ muhammadbilal.akram@uhasselt.be (M.B.A.); davy.janssens@uhasselt.be (D.J.) \\ 3 College of Engineering and Technology, American University of the Middle East, Kuwait; \\ Moustafa.houda@aum.edu.kw (M.H.); marc.azab@aum.edu.kw (M.A.) \\ * Correspondence: sarmadriaz@nutech.edu.pk
}

Citation: Riaz, M.S.; Cuenen, A.; Polders, E.; Akram, M.B.; Houda, M.; Janssens, D.; Azab, M. Child Pedestrian Safety: Study of Street-Crossing Behaviour of Primary School Children with Adult Supervision. Sustainability 2022, 14, 1503. https://doi.org/10.3390/ su14031503

Academic Editors: Aleksandra Deluka-Tibljaš, Irena Ištoka Otković and Sanja Šurdonja

Received: 15 December 2021

Accepted: 21 January 2022

Published: 27 January 2022

Publisher's Note: MDPI stays neutral with regard to jurisdictional claims in published maps and institutional affiliations.

Copyright: (C) 2022 by the authors. Licensee MDPI, Basel, Switzerland. This article is an open access article distributed under the terms and conditions of the Creative Commons Attribution (CC BY) license (https:// creativecommons.org/licenses/by/ $4.0 /)$.

\begin{abstract}
Road traffic accidents are the primary cause of injuries and fatalities among children. The current study focuses on children's (un)safe crossing behaviour in a real traffic situation accompanied by an adult at a crosswalk in front of their school. The study aims to investigate if there are differences in crossing behaviour related to road infrastructure (i.e., one-way and two-way street, elevated and non-elevated street crossing), the gender of the child, and the effect of the accompanying adult's behaviour on the child's crossing behaviour. Primary school children from two urban schools in Flanders (Belgium) were observed for three days while crossing the street in front of their school in the morning and afternoon. A total of 241 child-adult pairs were observed. Descriptive analysis, Pearson chi-square tests, and binary logistic regression models were used to find differences between groups. More than half of the crossings exhibited two or more unsafe behaviours. Not stopping at the curb before crossing was the most unsafe behaviour, exhibited by $47.7 \%$ of children; not looking for oncoming traffic before and during the crossing was the second most unsafe behaviour, exhibited by $39.4 \%$ of the children. The only difference between boys' and girls' crossing behaviour was in stopping at the curb with girls 1.901 times more likely to stop before crossing as compared to boys. Adults holding hands of the child resulted in safer behaviours by children. The children not holding hands displayed significantly riskier behaviour in running or hopping while crossing the street and being distracted. The study reinforces the need to improve the transportation system through infrastructural interventions (elevated crosswalks), as well as educating and training children and the parents on safe crossing behaviour in traffic.
\end{abstract}

Keywords: traffic safety; children crossing behaviour; infrastructure; binary logistic regression

\section{Introduction}

\subsection{Traffic Accidents among Children}

Road traffic injury is the leading cause of death among children, and is the fourth leading cause of death in children between the age of 5 and 14 years [1-3]. Children are highly involved in these statistics as they have a share of $38 \%$ in the total number of pedestrian fatalities [4]. Data from the European Union also shows that children are often involved in traffic accidents in urban and residential areas near schools [5].

In Belgium, the risk of a 6 to a 14-year-old pedestrian being involved in a traffic accident is 10.5 times higher than an average car driver [6]. The residents of the Flanders region in Belgium prefer walking and cycling, thirty percent more than an average Belgian, which exposes them to traffic conditions $[7,8]$. According to the World Health Organization (2013), around 70\% of all pedestrian fatalities in the European Union occurred in urban areas 
as they pose a higher risk to pedestrians [9]. In Belgium, the pedestrians were involved in $28 \%$ of the fatalities, which is lower than the European average of $40 \%$ [10].

\subsection{Street Crossing Behavior of Children}

There has been a lot of research on what children focus on when they attempt to cross a street safely and what constitutes as a risky behaviour [11-14]. Before children apply the rules to cross a street, they need to identify the situation as safe or unsafe by judging the speed and proximity of oncoming traffic. To make the correct decision, the child must first stop and observe the traffic situation. Children in Belgium are taught in schools to look left, right, and left again before crossing the street.

Children get involved in traffic accidents due to several factors which are mostly beyond their control. These factors are behavioural and physical in nature [15-17]. The primary behavioural factors include lack of ability to scan the traffic situation for threats properly, inability to estimate speed and distance [18], inattention [19], distraction (playing, talking, mobile phone use) [20-23], unpredictable behaviour, and noncompliance with the rules and regulations [18]. The primary physical factor is having a different perspective of the traffic environment due to their small posture, making it challenging for them to see oncoming traffic [24]. The small posture of children also affects the drivers as it becomes difficult for them to detect children. At proximity, they can be undetectable below the motorized vehicle height [25]. Street crossing requires the skills mentioned above that young children lack (e.g., knowledge about traffic laws, visual searching ability, risk detection, and perception). Younger children are at risk as these skills are developed with experience and age [22]. Children are also not aware of dangerous situations in traffic due to their inability to coordinate eyesight and hearing [26]. For children aged 6 to 10 years, their attentional skills are still being developed, putting them at a higher risk than adults when crossing the street while distracted [27]. The lower attentional capacities of children aged 6 to 10 while distracted makes them less capable of identifying safe places to cross the street [28]. There has been empirical evidence showing that boys tend to exhibit riskier behaviours than girls. A study on perceived risk among primary school children (age 6-10 years) found that boys and girls differ in appraising a given dangerous situation, with boys rating risk lower than girls [29]. Furthermore, boys have a lot more confidence in their abilities while underestimating the risk in any dangerous situation than girls [30].

To cross safely, children need to prevent distracting activities that may lead them to not paying attention to critical environmental information and cross within the crosswalk lines [31,32]. Not stopping at the curb and observing the traffic is related to distraction and increases the risk of an accident [33].

\subsection{Adult Supervision}

Adult supervision is considered an essential behavioural technique for reducing child pedestrian involvement in accidents. Morrongiello and Barton [34] define adult supervision as the physical proximity of the adult to the child. The efficacy of surveillance has been demonstrated in several studies [11,35]. The supervision affects the children's pedestrian safety as the supervising adult can intervene physically or verbally if the child behaves in an unsafe way. The efficacy of such an intervention is somewhat apparent as the adult who is holding hands with a child can restrain the child physically before crossing the street.

Furthermore, holding hands (direct physical contact) with the child can help adults restrain a child who may behave impulsively; such supervision is particularly vital when peers are present during the crossing manoeuvre [34]. It is still unclear what level of control is necessary for a child to behave safely in traffic. Research has shown that adult supervision influences the behaviour of the accompanying child, but it does not guarantee the child's safety during the crossing manoeuvre [36]. Previous research efforts have looked at the effect of the adult on the accompanying child [12] and the gender differences in street crossing behaviours [37]. A study about child pedestrian injuries circumstances reported 
that, in $36 \%$ of the cases, a supervisor was present, and in more than half of the cases, the supervisor was within an arm's reach of the child [38,39].

\subsection{Impact of Infrastructure on Pedestrian Safety}

Researchers have shown that the transportation system has significantly ignored the safety of children in traffic $[40,41]$, and how the responsibility is generally located with the child in traffic. Previous research focusing on child pedestrian fatality during crossing of a street found that the mean time available for crossing, assuming a steady flow, resulted in running as a necessary prerequisite for road crossing, rather than as an indication of impulsiveness of the child [40].

As school children are primarily involved in accidents within 500 meters of the school gate [42], their behaviour should be observed in the school's proximity, and the impact of the environmental factors should also be considered. In terms of pedestrian safety, there are benefits of both one-way and two-way streets. Generally, one-way streets can simplify the crossing behaviour for pedestrians, as they must look for traffic in one direction only. Research has also shown that one-way streets result in fewer road traffic accidents involving pedestrians [43]. Two-way streets also appear to be difficult for child pedestrians to cross [44]. A naturalistic behavioural observation study of pedestrians by Oxley et al. [45] showed that more unsafe crossing behaviours were recorded on two-way streets than on one-way streets.

However, one-way streets can encourage motorists to travel at higher speeds, and intersections involving one-way streets can confuse child pedestrians [46]. There is also evidence of increased conflicts between vehicles and pedestrians within a one-way-street network than in a comparable two-way system. This increase in conflicts is because of additional turning movements at the intersections caused by drivers who have to travel out of direction to reach their destination. These additional turning movements typically increase $30-40 \%$ of pedestrian-vehicle conflicts within a one-way street network compared to a similar two-way street network [47]. In a one-way street network, there is also a safety concern for pedestrians as there is an increased confidence level on the part of pedestrians and higher speeds on the part of the driver [48].

Midblock pedestrian crossings are designated areas for pedestrians to cross the street [49] and provide priority to pedestrians to cross over motorized vehicles [50]. Vehicles must yield to the pedestrians in this area in case both entered the crosswalk area at the same time. Another infrastructural measure taken to improve pedestrian visibility in pedestrian crossing and to reduce speeds of oncoming traffic is elevated/raised crosswalks [51]. Elevated crosswalks have shown to positively affect the occurrence of accidents involving children [52]. Sweden has implemented various full scale demonstration projects related to the "Vision Zero" project, with measures taken to improve the infrastructure for safe mobility of pedestrians and cyclists, including elevated crosswalks and intersections $[53,54]$.

\subsection{Research Aims and Objectives}

A recent scoping review of behavioural observation studies found an absence of empirical data on child pedestrian behaviour near primary schools in Belgium [55]. Consequently, this study sought to offer empirical data on the child's safety when crossing the street in front of their school and to add to the empirical knowledge base about indicators of risky behaviour displayed by children near their schools in Flanders (Belgium). Currently, there is no clear understanding of child pedestrian behaviour on crosswalks accompanied by an adult.

Furthermore, the study aims to understand the effect of infrastructure (one-way street and two-way street, elevated and not elevated crosswalk) on the crossing behaviour of pedestrians, which has not been studied before for child pedestrians. The study also seeks to understand the impact of gender and the behaviour of the accompanying adult on the behaviour of the child. Based on the objectives of the research, the following research questions are formulated: 
1. Do children's (un)safe behaviors on crosswalks differ between schools located at one-way and two-way streets and between elevated and non-elevated crosswalk?

2. Does the behavior between boys and girls while crossing differ? Are there differences in behaviors of boys and girls on crosswalks in front of their schools?

3. Does the behavior of the accompanying adult affect the behavior of the child?

\section{Methodology}

\subsection{Study Design}

The study aims to understand the crossing behaviour of child pedestrians in front of their school. The study design is cross-sectional. Pedestrians (ages 6-12) from two primary schools in Hasselt and Genk (Flanders, Belgium) were observed for three mornings and three afternoons at each school while crossing the zebra crossing in front of their school. As adults accompanied most pedestrian children in primary schools, only the behaviour of accompanied children was recorded. The research was approved by both participating schools.

\subsection{Selection of Study Locations}

Two urban primary schools were selected for data collection in Hasselt and Genk (Flanders, Belgium). Table 1 presents the characteristics of both study locations. The two selected schools, as well as the environmental characteristics, are shown in Figures 1 and 2. As both schools are situated in an urban environment, there were cars parked near the school when parents dropped their children in the morning and picked them up in the afternoon.

Table 1. Characteristics of study locations.

\begin{tabular}{ccc}
\hline Characteristics & One-Way Street School & Two-Way Street School \\
\hline Number of lanes & 1 & 2 \\
Lane width & $2.5 \mathrm{~m}$ & $3.7 \mathrm{~m}$ \\
Speed limit & $30 \mathrm{~km} / \mathrm{h}$ & $30 \mathrm{~km} / \mathrm{h}$ \\
Direction of traffic & One side for traffic except for cyclists and mopeds & Both sides \\
Cycle Lane & No & No \\
Parking space & On one side (next to the school) & Both sides \\
Zebra crossing & Level & Elevated \\
Area & Urban & Urban \\
\hline
\end{tabular}
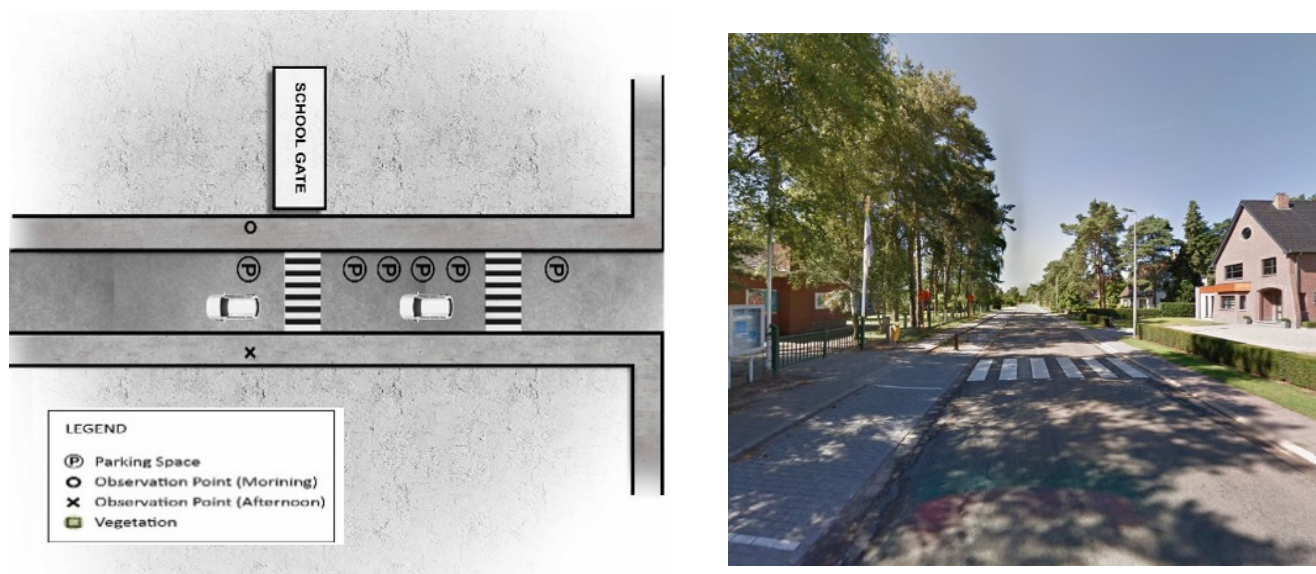

Figure 1. Left: Schematic description of road layout at one-way street school (Genk, Belgium). Right: Image of the street (Genk, Belgium). 

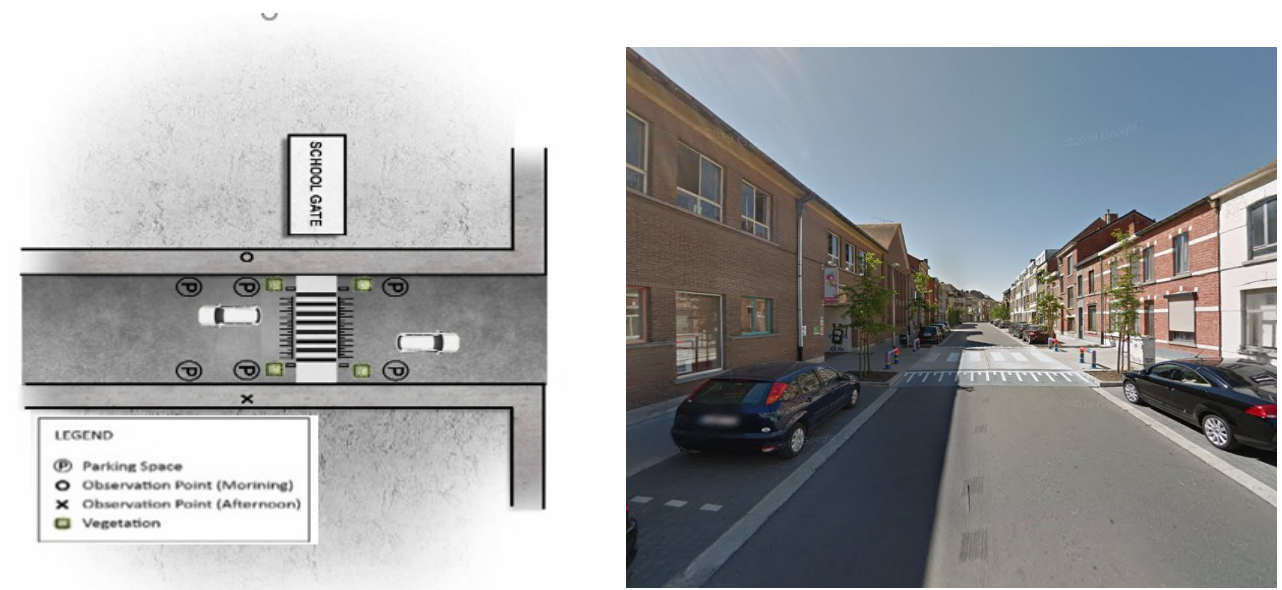

Figure 2. Left: Schematic description of road layout at two-way street school (Hasselt, Belgium). Right: Image of the street (Hasselt, Belgium).

The second school is located near a two-way street with parked cars on both sides of the road. The crossing area is slightly elevated, as shown in Figure 2.

\subsection{Observation Protocol}

Two observers observed each school crosswalk independently. The observers were standing near the gate during the morning observation and across the entrance during the afternoon observation, as shown in Figures 1 and 2. The observers positioned themselves so that children could be observed clearly, and all the behavioural indicators can be noted. Child-adult pairs were observed during the morning from 8:00 a.m. to 8.45 a.m. (15 min before the opening of the school gate and $30 \mathrm{~min}$ after the opening of the school gate) and in the afternoon from 3:00 p.m. to 3:45 p.m. (45 min after the opening of the school gate) for three days per school (Tuesday, Thursday, and Friday) in April-May 2019. An observation grid was developed to register the behavioural indicators. The grid included the gender and the behavioural indicators of the child and the accompanying adult. The gender of the child and adult were visually estimated. The behavioural indicators are coded dichotomously except for the looking behaviour (i.e., not looking, one side, both sides, or left, -right, and left). If a child is distracted, the distracting element was noted as well. The following behavioural indicators were developed and adopted based on previous studies $[12-14,37,56]$. The following behaviours were recorded:

(a) Stopped at the curb: The pedestrian stops at the curb before crossing instead of waiting or failing to stop.

(b) Looking behaviour (before and while): The child looks left, right, and then left again before crossing, and does not ignore oncoming traffic in one or both directions. This behaviour was coded as not looking, looking at one side, looking at both sides and "perfect" looking where a child looks left, right, and left again. The looking behaviour was also coded for the accompanying adult.

(c) Runs across the lane: The child runs or hops across the street.

(d) Crosses at the pedestrian crossing: The child uses the pedestrian crosswalk to cross and does not cross diagonally.

(e) Distraction: Talking, playing with an object. Distraction was coded for the accompanying adult and the child.

(f) In addition to the behavioural aspects, other safety aspects were recorded for each child, i.e., if the child wore a bright reflective jacket (yes or no);

(g) Whether the child and accompanying adult held hands while crossing (yes or no) [56]. 


\subsection{Ensuring the Reliability of Data Collection}

Each behaviour was defined according to the literature review and during a pilot observation session at each school to maximise the interrater agreement on the coded behaviours. Interrater reliability measures the extent to which independent observers evaluating the same situation reach the same conclusion [57]. High interrater reliability (high agreement) between independent observers is considered the theoretical solidity of the observation methods and the training of the observers. A low level of interrater reliability suggests inadequate training of observers and operational definitions [58].

\subsection{Data Analysis}

Data were primarily analysed using descriptive methods; the frequency and percentage of each coded behaviour were computed for each location separately and combined. Pearson chi-square tests to test street-crossing behaviour differences among groups (gender, school, accompanying adult) were also performed. All the analyses were carried out at a 95\% confidence level. The interrater reliability was assessed by two measures: Cohen's $\mathrm{K}$ and percent agreement. Cohen's $\mathrm{K}$ is considered a more favourable reliability measure than percent agreement [57]. Cohen's $\mathrm{k}$ corrects percent agreement for agreement by chance, while percent agreement only expresses the percentage of cases where the independent observers agree. A value of 0.80 for Cohen's $\mathrm{K}$ is acceptable for behavioural observation studies [57].

The data are analysed with binary logistic regression analysis, which can predict the probability $(P)$ of a specific event when the dependent variable is dichotomous [59]. In this study, the occurrence of a specific crossing behaviour indicator can be considered as a binary response variable. The log odds (logit) of $P$ equals the natural logarithm of $\frac{P}{1-P}$. Binary logistic regression estimates the log odds of the independent variables as a linear combination as shown in the equation below:

$$
\operatorname{Logit}(P)=\operatorname{Ln}\left(\frac{P}{1-P}\right)=\beta_{0}+\beta_{1} X_{1}+\beta_{2} X_{2}+\ldots+\beta_{n} X_{n}
$$

In this equation, $P$ is the probability of the behaviour occurrence; $X_{n}$ is the independent variable; and $\beta_{n}$ is the logistic regression coefficient. For each research question, the significance value of 0.05 was accepted as influential predictor variables. For each model, the odds ratio was calculated to determine if there is an increase $(>1)$ or decrease $(0-1)$ in the probability of the behaviour when the independent variables increase with one unit [52]. The Hosmer-Lemeshow test is used to assess each model's goodness of fit. The test determines whether the observed event rates match expected event rates. For the Hosmer-Lemeshow test, $p>0.05$ shows that the model fits the data [53]. SPSS 25.0 is used for all analyses.

\section{Results}

\subsection{Descriptive STATISTICS}

There were 241 adult-child pairs observed: 127 crossings were observed near the school at the one-way street, while 114 crossings were observed near the school at the two-way street (Table 2).

\subsection{Interrater Reliability}

There was a high agreement in all behavioural indicators coded by the two observers with Cohen's kappa values greater than 0.80 and more than 90 percent agreement for all behavioural variables (Table 3). Disagreements in the behavioural indicators observed were removed from the analysis and only the data where there were no discrepancies between observers was used for analysis. Consequently, both interrater reliability measures indicate high interrater reliability in the collected data. 
Table 2. Descriptive statistics.

\begin{tabular}{cccc}
\hline Variable Name & \multicolumn{2}{c}{ Infrastructure } & Total \\
\hline Demographic Variable & $\begin{array}{c}\text { School 1 } \\
\text { (One-Way Street) }\end{array}$ & $\begin{array}{c}\text { School 2 } \\
\text { (Two-Way Street) }\end{array}$ & \\
\hline Gender (child) & Number (\%) & Number (\%) & Number (\%) \\
Boy & $76(59.8)$ & $67(58.8)$ & $143(59.3)$ \\
Girl & $51(40.2)$ & $47(41.2)$ & $98(40.7)$ \\
Male & Number (\%) & Number (\%) & Number (\%) \\
Fender (accompanying adult) & $45(35.4)$ & $39(34.2)$ & $84(34.9)$ \\
Weekdays & $82(64.6)$ & $75(65.8)$ & $157(65.1)$ \\
Tuesday & Number (\%) & Number (\%) & Number (\%) \\
Thursday & $39(30.7)$ & $37(32.4)$ & $76(31.5)$ \\
Friday & $43(33.8)$ & $43(37.7)$ & $86(35.7)$ \\
Behavioural indicators & $45(35.4)$ & $34(29.8)$ & $79(32.8)$ \\
Not Stopping at curb & Number (\%) & Number (\%) & Number (\%) \\
Not looking for traffic & $51(40.2)$ & $64(56.1)$ & $115(47.7)$ \\
Running across the crosswalk & $46(36.2)$ & $49(43.0)$ & $95(39.4)$ \\
Distraction & $34(26.8)$ & $29(25.4)$ & $63(26.1)$ \\
Not crossing within the crosswalk & $35(27.6)$ & $12(10.5)$ & $47(19.5)$ \\
Holding hands of accompanying adult & $65(51.2)$ & $15(13.2)$ & $80(33.2)$ \\
Safety measure & $58(45.7)$ & $40(35.1)$ & $98(40.6)$ \\
Fluorescent jacket & Number (\%) & Number (\%) & Number (\%) \\
\hline
\end{tabular}

Table 3. Interrater reliability.

\begin{tabular}{ccccc}
\hline & \multicolumn{2}{c}{ One-Way Street } & \multicolumn{2}{c}{ Two-Way Street } \\
\hline Behavior Observed & Cohen's k & Percent Agreement & Cohen's k & Percent Agreement \\
\hline Not stopping at the curb & 0.820 & 91.3 & 0.909 & 95.4 \\
Looking behavior (Child and/or adult) & 0.885 & 96.7 & 0.937 & 98.5 \\
Looked at both sides & 0.875 & 96.3 & 0.932 & 98.2 \\
Distraction while crossing & 0.900 & 98.3 & 0.958 & 98.3 \\
Running across the crosswalk & 0.833 & 96.7 & 0.916 & 98.2 \\
Crossing within the crosswalk lines & 0.961 & 99.2 & 0.981 & 99.1 \\
Child holding hands of the accompanying adult & 0.968 & 98.4 & 0.974 & 98.7 \\
\hline
\end{tabular}

\subsection{Effect of Infrastructure on Crossing Behavior}

Five behavioural indicators are analysed using the Pearson chi-square test and binary logistic regression models to analyse the influence that the road infrastructure (one-way vs. two-way street, and elevated vs. level crosswalk) has on children's crossing behaviour. As shown in Figure 3, there are significant differences between the two schools in "not stopping at the curb", "distraction", and "not crossing within the crosswalk line". The school children near the two-way street stopped at the curb significantly less than the children of the school near the one-way street, $\chi^{2}(1)=6.15, p=0.013$. Furthermore, the school children near the one-way street are more distracted, $\chi^{2}(1)=11.10, p<0.001$. Another significant difference is that at the school near the one-way street, more than half the children did not cross within the crosswalk lines. In contrast, at the school near the two-way street which had an elevated crosswalk, this was only $13.2 \%, \chi^{2}(1)=39.16$, $p<0.001$.

Table 4 presents the binary logistic regression model results predicting the likelihood of certain behaviours at the one-way street school compared to the two-way street school. The model was built using all behavioural indicators as independent variables predicting the behaviour at the one-way street and two-way street (dependent variable). The model was tested for goodness of fit with the Hosmer-Lemeshow test, $\chi^{2}(8)=11.071, p>0.198$, which shows that the model fits the data $(p>0.05)$. The model shows significant differences between the one-way and two-way streets in not stopping at the curb, distraction while crossing, and not crossing within the crosswalk lines. The model predicts that the probability of not stopping at the curb is 3.020 times more likely at the two-way street, while 
distraction and not crossing within the crosswalk lines is 0.254 and 0.094 times less likely in the two-way street. The model also predicts that accompanying adults held children's hands more often (2.572 times) in one-way street schools.

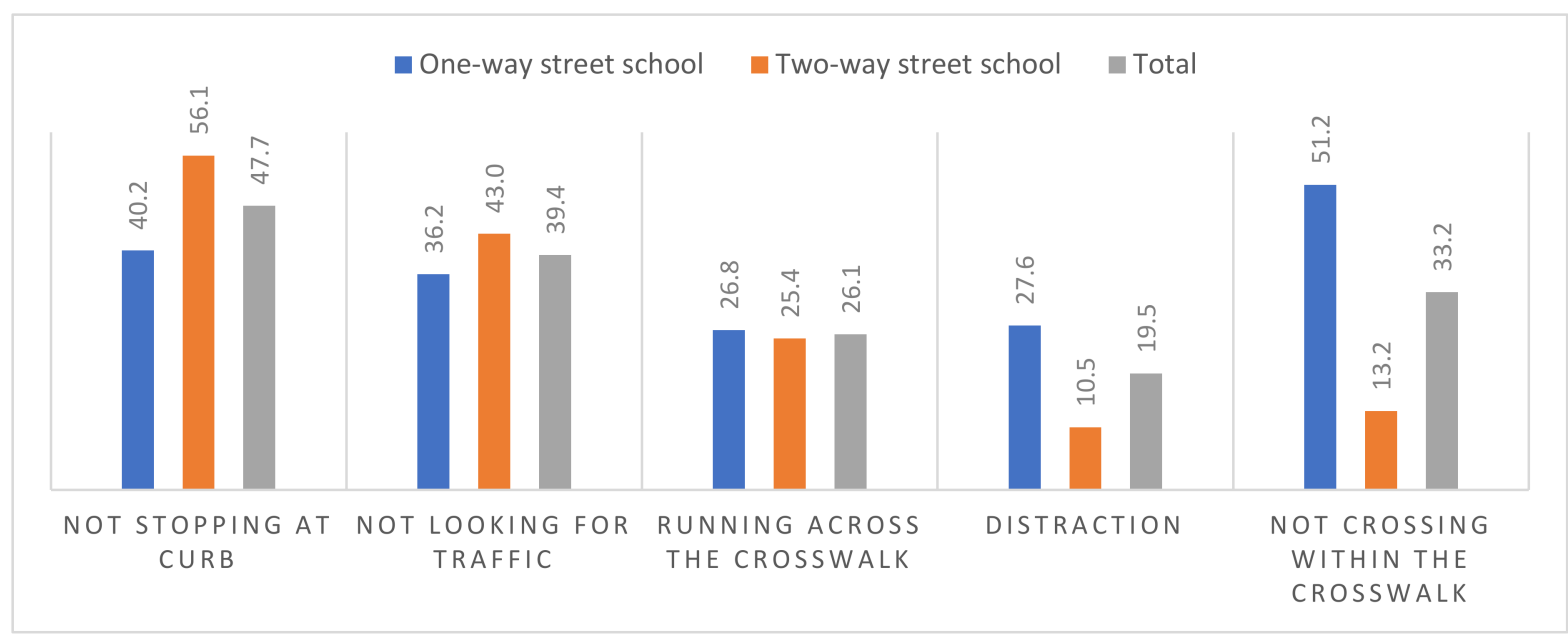

Figure 3. Difference between indicators of behaviour between one-way school and two-way school.

Table 4. Binary logistic regression results.

\begin{tabular}{|c|c|c|c|}
\hline \multicolumn{4}{|c|}{ Logistic Regression Results ( $=241$ ) } \\
\hline Variable & $\begin{array}{l}\text { Infrastructure }(\text { School at } \\
\text { One-Way Street = 127, } \\
\text { and School at } \\
\text { Two-Way Street }=114)\end{array}$ & $\begin{array}{c}\text { Gender } \\
(\text { Boys }=143, \text { Girl }=98)\end{array}$ & $\begin{array}{l}\text { Holding Hands of } \\
\text { Accompanying Adult } \\
(Y=98, N=143)\end{array}$ \\
\hline Intercept & -0.427 & -0.358 & -0.117 \\
\hline Gender & $0.329(1.390)^{*}$ & na & $0.433(1.542)^{*}$ \\
\hline Infrastructure & na & $0.338(1.402) *$ & $0.896(2.449)^{* * * *}$ \\
\hline \multicolumn{4}{|l|}{ Behavioral indicators } \\
\hline Not stopping at curb & $1.105(3.020)^{* * * *}$ & $0.647(\mathbf{1 . 9 1})^{* * *}$ & $-0.158(0.854)^{*}$ \\
\hline Not looking for traffic & $-0.142(0.868)^{*}$ & $0.156(1.169) *$ & $-0.580(\mathbf{0 . 5 6 0})^{* * *}$ \\
\hline Running across the crosswalk & $0.381(1.464)^{*}$ & $0.239(1.27)^{*}$ & $-0.703(\mathbf{0 . 4 9 5})^{* * *}$ \\
\hline Distraction & $-1.371(\mathbf{0 . 2 5 4})^{* * * *}$ & $0.031(1.032) *$ & $-1.237(\mathbf{0 . 2 9 0})^{* * * *}$ \\
\hline Not crossing within the crosswalk & $-2.367(0.094)^{* * * *}$ & $-0.375(0.687) *$ & $-0.704(\mathbf{0 . 4 9 5})^{* * *}$ \\
\hline Holding hands & $0.945(2.572) * * * *$ & $0.433(1.542) *$ & na \\
\hline $\begin{array}{l}\text { Hosmer-Lemeshow } \\
\text { test/Nagelkerke R squared }\end{array}$ & $\begin{aligned} X^{2} & =11.070(\mathrm{df}=8 \\
p & =0.198) / 0.343\end{aligned}$ & $\begin{aligned} X^{2} & =1.742(\mathrm{df}=8 \\
p & =0.988) / 0.05\end{aligned}$ & $\begin{array}{c}X^{2}=7.758(\mathrm{df}=8 \\
p=0.457) / 0.151\end{array}$ \\
\hline
\end{tabular}

Note: Values present parameter estimates of logistic regression models. The odds ratio in parenthesis, with $p<0.05$, are in bold type. ${ }^{*} p>0.10$ [not significant at $90 \%$ confidence interval $(\mathrm{CI})$ ]; ${ }^{* * *} p \leq 0.05$ (significant at $95 \% \mathrm{CI}$ ); ${ }^{* * * *} p \leq 0.01$ (significant at $99 \% \mathrm{CI}$ ). For the Hosmer-Lemeshow test, $p>0.05$ shows that the model fits the data. na: not applicable.

\subsection{Effect of Gender on Crossing Behavior}

Concerning the influence of gender on children's crossing behaviour, there were no significant differences found among boys and girls in crossing behaviour at each school. Still, across both schools, a significant effect was seen with not stopping at the curb. Specifically, boys exhibit this unsafe behaviour significantly more than girls, $\chi^{2}(1)=4.155$ $p=0.042$. The binary logistic regression predicts that girls had 1.91 times higher odds to 
exhibit the safer behaviour of stopping at the curb before crossing. Figures 4 and 5 present the unsafe behaviour exhibited by both genders at each site.

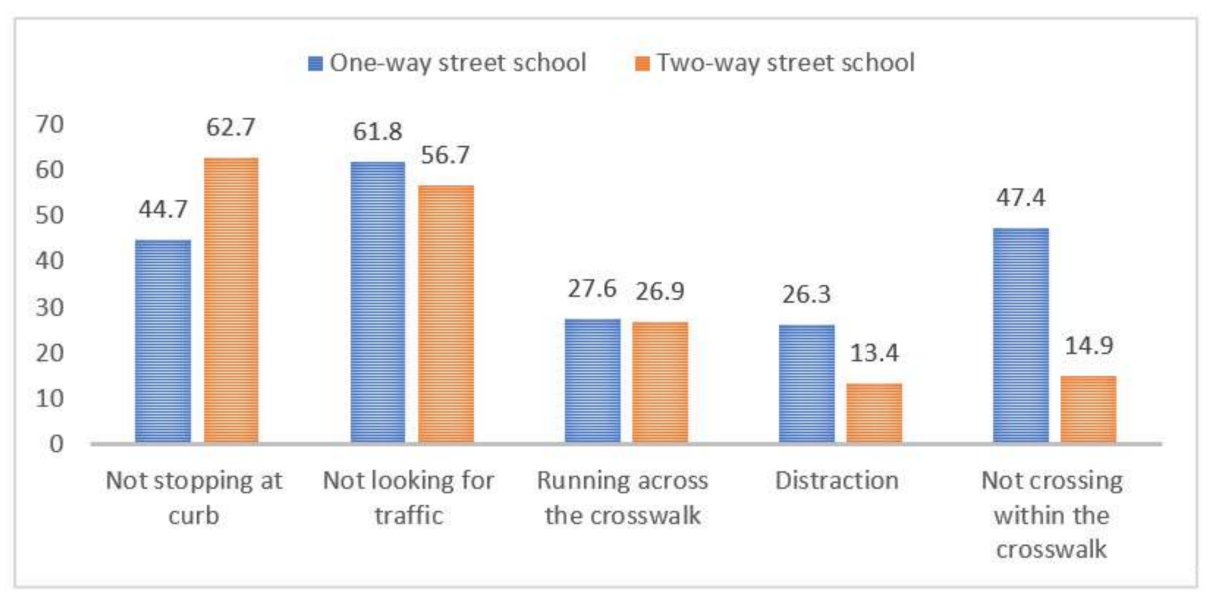

Figure 4. Unsafe crossing behaviour exhibited by boys across both sites.

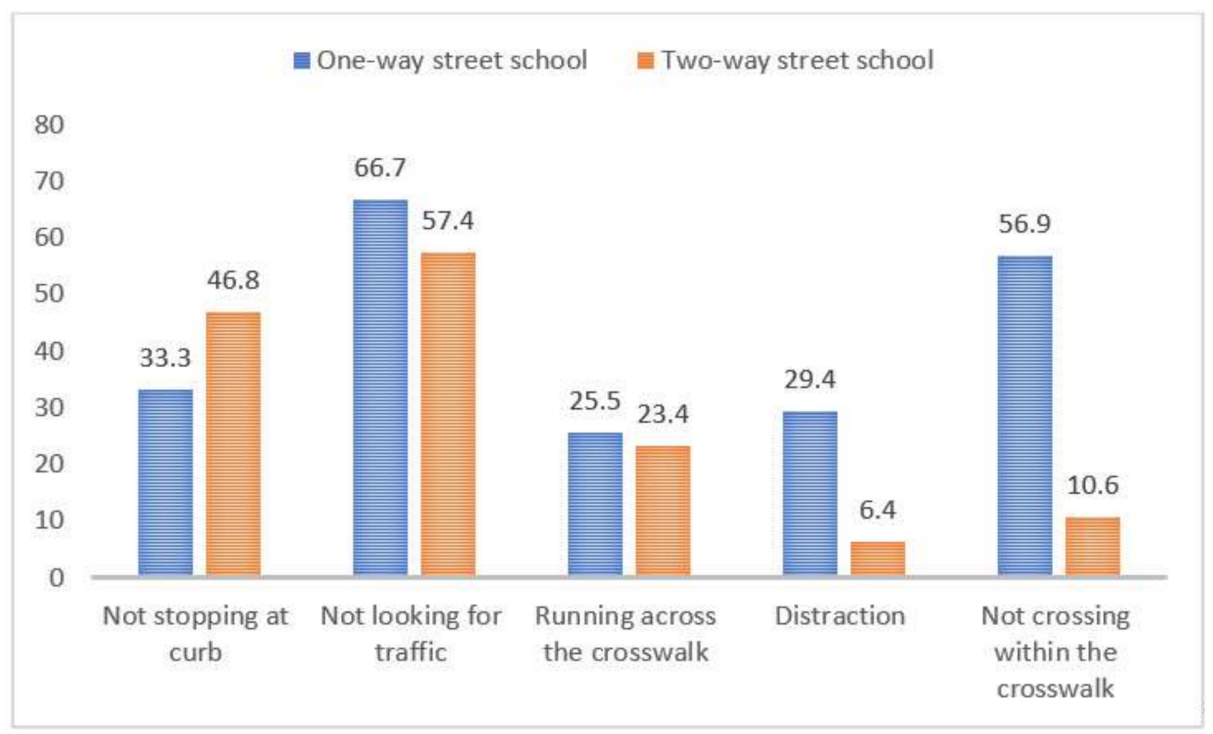

Figure 5. Unsafe crossing behaviour exhibited by girls across both sites.

\subsection{Effect of Accompanying Adult Behavior on Children Crossing Behavior}

The accompanying adults' behaviour was mainly safe, with only ten adults (4.1 percent) not looking for oncoming traffic, and 15 adults (6.2 percent) who were distracted while crossing. Adults not looking for traffic and being distracted resulted in more children significantly not stopping at the curb before crossing, $\chi^{2}(1)=11.431, p=0.001$ and $\chi^{2}(1)=4.207, p=0.04$, respectively. The risky behaviours were summed to create a "risky behaviour score" out of five. Ninety-eight adults were holding hands of the accompanying children (36.6\% boys and $46.9 \%$ girls), while 143 did not. While checking the effect of this on children's behaviour, significant differences were found between the two groups with the ones not holding hands performing significantly more risky behaviours, $\chi^{2}(4)=16.96$, $p=0.002$. Figure 6 presents the differences in behavioural indicators between children holding hands and not holding hands of the accompanying adult. 


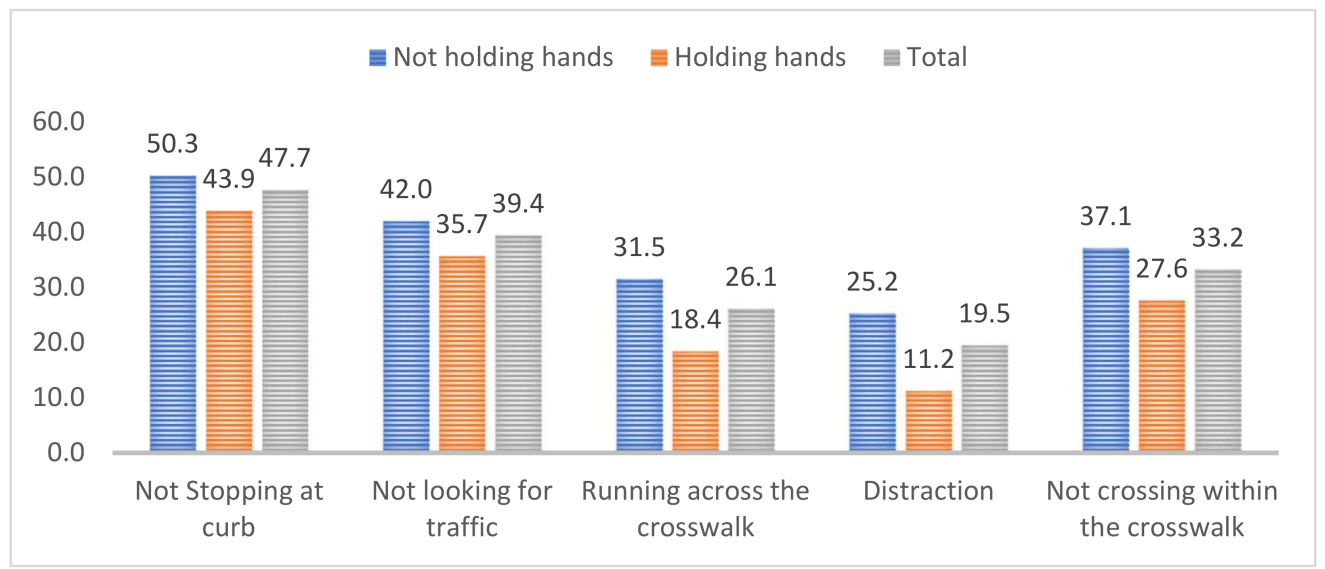

Figure 6. Effect of accompanying adult behaviour on child's behaviour.

The children not holding hands also displayed significantly riskier behaviours in running or hopping behaviour and being distracted, $\chi^{2}(1)=5.169, p=0.023$ and $\chi^{2}(1)=7.209$, $p=0.007$, respectively. Table 4 presents the results from the binary logistic regression predicting the likelihood of the behaviour of children holding hands compared to children not holding the hands of the adult. The Hosmer-Lemeshow test shows that the model fits the data, $\chi^{2}(8)=11.070, p=0.198$. The results show that the children holding hands perform significantly safer behaviours and are less likely to perform unsafe behaviours. The children holding hands are less likely to not look for traffic ( 0.560 times), run across the crosswalk (0.495 times), be distracted (0.290 times), and not cross within the crosswalk (0.495 times), as compared to the children not holding hands of the accompanying adult.

\section{Discussion}

The current study aimed to observe the crossing behaviour of child pedestrians in front of two urban schools in Flanders, Belgium, in order to understand what unsafe behaviours children exhibit on crosswalks outside their schools, and the effect of accompanying adult, infrastructure, and gender in crossing behaviour.

Although measures and methods have been developed to reduce the number of fatalities among vulnerable road users, child pedestrian safety remains an important issue. Educational strategies to enhance children's safety include lessons and training in protected areas or actual traffic situations and other creative techniques such as traffic safety games. Enforcement involves strategies (e.g., speed limits) to deter all road users from unsafe behaviours and encourage them to obey traffic laws, especially in a school zone, by reminding motorists to slow down and obey the speed limit. Enforcement in school zones also involves appointing "crossing guards" around schools to safely help children cross the street. The transportation system should improve the pedestrian safety in traffic by reducing accidents and making them less severe as per the "vision zero" aspirations [60].

Around half the children were observed exhibiting two or more unsafe behaviours. Approximately one-fourth of the children were running or hopping while crossing the crosswalk, while one-fifth were distracted. Around forty percent of the children did not look for traffic while crossing, and almost half did not stop before crossing, which is less than the more than $60 \%$ observed by Zeedyk, Wallace [13]. The finding of children crossing in a straight line is in concordance with the results of a similar French study for accompanied children (supervised by adults), with two-thirds of the children staying within the lines of the crosswalk [37]. As regards not looking for traffic, one of the most prominent unsafe behaviours exhibited by children in the current study, these results are similar to behavioural observation studies on children, which identified not looking for traffic as the most prominent unsafe behaviour exhibited by children $[11,13,61]$. As the age group observed are primary school children aged $6-12$, there are some trends of dangerous behaviour across this age group, as shown by Rosenbloom et al. [14], including that around 
half the children did not look for oncoming traffic within the age group of 7-11 year olds. A study on 5-6-year-old pedestrians [13] has similar results, with only $40 \%$ looking for traffic. The finding makes it essential for children to be visible to the oncoming traffic as they are not looking for traffic themselves. The school near the one-way street had almost $80 \%$ wearing fluorescent vests, while the school near the two-way street had no children wearing any reflective jacket. One of the safety measures that children can take is to wear brightly coloured clothing to be conspicuous. This safety measure involves being seen by oncoming traffic and, most critically, by motorized vehicles [62]. The reflective vests worn by children can significantly increase children's visibility to oncoming traffic, especially in winter months, to avoid accidents [63].

When the effect of infrastructure is investigated, it is evident that there are differences in crossing behaviours at the one-way street and the two-way street. Children stopped significantly less at the curb in the two-way street than the school near the one-way street $(p=0.013)$. Furthermore, the children are more distracted $(p=0.001)$ and significantly do not cross within the crosswalk lines $(p=0.001)$ at the school near the one-way street. The elevated crosswalk with extra safety infrastructure at the school near the two-way street resulted in pedestrians crossing within the crosswalk instead of crossing it diagonally. Even though one-way streets simplify pedestrians' looking behaviour as they must look at one side only for traffic, there were no significant differences found in looking behaviour of children in this study with children not looking.

The study found significant differences in not stopping at curb behaviour among boys and girls, with boys exhibiting this unsafe behaviour more often. There were no other significant differences between boys and girls in other risky behaviours. This aligns with the findings of Barton and Schwebel [36], who found that girls are more cautious while crossing compared to boys.

To understand the effect of the accompanied adult on the child's behaviour, it was observed that child pedestrians not holding hands exhibited unsafe behaviours, like being distracted while crossing and running or hopping across the crosswalk. Another aspect of adult supervision shows that adults held hands more often with girls than with boys. This can imply that adults believe that girls need more protection or control, despite boys having been empirically shown to be more impulsive in traffic [12,36]. Another worrying observation during the data collection is that the adults did not ensure that children observe and monitor the traffic situation before crossing, mainly since not looking for oncoming traffic before crossing significantly contributes to more traffic accidents with children [64]. Adults can use this opportunity to train and teach children to cross the street safely, but they do not typically use this opportunity when crossing with them [12,65]; this was also observed in the current study.

\section{Limitations and Future Research}

The study has some weaknesses. The first limitation is that only urban schools were selected for data collection. Behaviour across schools may vary somewhat, and also across urban and rural schools $[66,67]$. Both schools in this study are in a street with no central isolation zone, as these streets are often seen in most urban localities in Belgium. Data was collected for a limited number of days, although the behavioural patterns are clear and would likely reoccur with further observation and data collection. Future studies can include comparative data analyses across research sites.

The second limitation is that although behaviour observation has many benefits, it has some inherent weaknesses such as lack of information of potential covariates (e.g., child road experience, personality, cognitive skills) that may have impacted the behaviour.

Future research can look at employing video observation to observe children's behaviour. The children can be identified with the help of the school administration. In that case, more information can be collected (i.e., experience, personality, and the child's age). Additional information about the child can help establish if there are significant differences between the grades of primary school children. Future research can also include the collec- 
tion of traffic data, and collection of data in peak and non-peak hours to understand their impact on behaviour of the child and the accompanying adult.

Future research can also include the gathering of information about the subjective assessment of the children about the crossing manoeuvre, using interviews after the crossing, e.g., do you think you have safely crossed the street? And why have you crossed the road in an unsafe way (e.g., not stopped at the curb)?

\section{Implications and Conclusions}

The study provides empirical data on child pedestrians' crossing behaviour in front of their school and provides implications to improve the safety of child pedestrians through education, engineering, and enforcement. Related to education, the current findings reinforce the need to teach and train children about various aspects of pedestrian and traffic safety. Younger children who are still learning to behave as safe pedestrians should not cross the street unsupervised. Younger children can benefit from road safety education tailored to their needs and adapted to their age, experience, and cognitive abilities [68,69]. Research has also shown that these behaviours can be improved by supervision in real situations and through simulation training [70]. Traffic safety education is part of the school curriculum in most of the European countries [63]. Education about traffic laws and training can help children stay safe while they are young. However, before teaching children through road safety education programs on how to behave in traffic, it is essential to first understand their behaviour [64]. Similar recommendations have also been made by other researchers in the EU [5]. Moreover, younger children can be educated about traffic safety at home by their parents using digital games which have shown to improve the performance of participants related to traffic safety [68].

Based on the current study results, the transportation system needs to further take into consideration their limitations and inexperience in traffic and improve the system to lower the danger for all users, including children [60,71]. Additionally, a road safety education is recommended, covering each aspect of safely crossing the street, i.e., stopping at the curb, monitoring the traffic, crossing within the crosswalk lines, and staying alert. The study also has implications for accompanied adults. However, adults were not the primary focus of this research. A few adults were also distracted and not looking for oncoming traffic. Adult behaviour in traffic can set an excellent example for children to follow and behave safely in traffic. Many studies have looked at the effect of this supervision on children's behaviour [34-36] and have also noted that, generally, adults do not take the opportunity to educate their children about correct behaviour in traffic [12]. Training interventions for improving child safety should also focus as a secondary target audience on the children's parents; the parents' knowledge and behaviour can also reflect the effect of the intervention on the children [72]. The findings in this study can also help to develop educational material for children in various forms of traffic education using classroom education and training in protected environments on both knowledge and skills [68,73].

Related to engineering, the road layout of the two-way street school resulted in the adult-child pairs crossing within the crosswalk lines; such a road geometry can help improve this safe behaviour at other crosswalks outside schools. The elevation of the crosswalk resulted in the pedestrians crossing within the crosswalk lines. Such an arrangement can encourage pedestrians to stay within the crosswalk lines while crossing. Elevated crosswalks also improve pedestrian safety by reducing vehicle speeds and increasing pedestrians' visibility, and have been recommended by the Federal Highway Administration [74] pedestrian safety guide and countermeasure selection system. The current findings reinforce the advantages of using an elevated crosswalk for pedestrians, and especially child pedestrians.

Related to enforcement, encouraging safer practices like reflective vests resulted in more than $75 \%$ of the children in the school at the one-way street wearing a reflective vest, while children of the school at the two-way street were not observed wearing any reflective vests. This can be because the school at the one-way street encouraged the children to wear 
the fluorescent jacket, while the school at the two-way street did not. As the children are performing unsafe behaviours and not looking for traffic, they must wear a reflective vest to be visible to the oncoming motorized vehicles in urban areas.

To conclude, the current study provides empirical data on child pedestrian crossing behaviour in Flanders (Belgium) and provides implications for improving the child's safety in traffic. The study also confirms that the crossing behaviour of children is influenced by the type of infrastructure, the gender of the child, and the accompanying adult's behaviour.

Author Contributions: Conceptualization, M.S.R., A.C., M.B.A., E.P. and D.J.; methodology, M.S.R., A.C., M.B.A., E.P. and D.J.; validation, A.C., E.P. and D.J; formal analysis, M.S.R., A.C., M.B.A., E.P. and M.H.; investigation, M.S.R., A.C., M.B.A. and E.P.; data curation, M.S.R. and M.B.A., writingoriginal draft preparation, M.S.R., A.C., M.B.A., E.P., M.H. and M.A.; writing-review and editing, M.S.R., A.C., M.B.A., E.P., M.H., M.A. and D.J.; visualization, M.S.R.; supervision, A.C., E.P. and D.J.; project administration, A.C., E.P. and D.J. All authors have read and agreed to the published version of the manuscript.

Funding: This research received no external funding.

Institutional Review Board Statement: Not applicable.

Informed Consent Statement: Not applicable.

Data Availability Statement: Data is contained within the article.

Acknowledgments: The authors would like to thank Krijs Brijs and Geert Wets for their guidance and constant feedback during this research. The authors also thank the two schools in Flanders, Belgium for their cooperation.

Conflicts of Interest: The authors declare no conflict of interest.

\section{References}

1. Ištoka Otković, I.; Deluka-Tibljaš, A.; Šurdonja, S.; Campisi, T. Development of models for children—Pedestrian crossing speed at signalized crosswalks. Sustainability 2021, 13, 777. [CrossRef]

2. WHO. Global Status Report on Road Safety; World Health Organization: Geneva, Switzerland, 2018.

3. Chang, F.R.; Huang, H.L.; Schwebel, D.C.; Chan, A.H.; Hu, G.Q. Global road traffic injury statistics: Challenges, mechanisms and solutions. Chin. J. Traumatol. 2020, 23, 216-218. [CrossRef] [PubMed]

4. WHO. Ten Strategies for Keeping Children Safe on the Road; World Health Organization: Geneva, Switzerland, 2015.

5. Deluka-Tibljaš, A.; Ištoka Otković, I.; Campisi, T.; Šurdonja, S. Comparative analyses of parameters influencing children pedestrian behavior in conflict zones of urban intersections. Safety 2021, 7, 5. [CrossRef]

6. Martensen, H. @RISK: Analysis of the Risk of Serious or Fatal Injuries in Traffic According to Age and Mode of Transport; Belgian Road Safety Institute-Knowledge Centre Road Safety: Brussels, Belgium, 2014.

7. Torfs, K.; Meesmann, U.; van den Berghe, W.; Trotta, M. ESRA 2015-The Results. Synthesis of the Main Findings from the ESRA Survey in 17 Countries; BRSI—Belgian Road Safety Institute: Brussels, Belgium, 2016.

8. European Commission. Belgium - Physical Activity Factsheet; European Commission: Brussels, Belgium, 2015.

9. WHO. Pedestrian Safety; World Health Organization: Geneva, Switzerland, 2013.

10. Comission, E. Traffic Safety Basic Facts 2018: Urban Areas; European Commission, Directorate General for Transport: Brussels, Belgium, 2018.

11. Schwebel, D.C.; Wu, Y.; Swanson, M.; Cheng, P.; Ning, P.; Cheng, X.; Gao, Y.; Hu, G. Child pedestrian street-crossing behaviors outside a primary school: Developing observational methodologies and data from a case study in Changsha, China. J. Transp. Health 2018, 8, 283-288. [CrossRef]

12. Zeedyk, M.S.; Kelly, L. Behavioural observations of adult-child pairs at pedestrian crossings. Accid. Anal. Prev. 2003, 35, 771-776. [CrossRef]

13. Zeedyk, M.S.; Wallace, L.; Spry, L. Stop, look, listen, and think?: What young children really do when crossing the road. Accid. Anal. Prev. 2002, 34, 43-50. [CrossRef]

14. Rosenbloom, T.; Ben-Eliyahu, A.; Nemrodov, D. Children's crossing behavior with an accompanying adult. Saf. Sci. 2008, 46, 1248-1254. [CrossRef]

15. Tabibi, Z.; Pfeffer, K.; Sharif, J.T. The influence of demographic factors, processing speed and short-term memory on Iranian children's pedestrian skills. Accid. Anal. Prev. 2012, 47, 87-93. [CrossRef]

16. Barton, B.K.; Morrongiello, B.A. Examining the impact of traffic environment and executive functioning on children's pedestrian behaviors. Dev. Psychol. 2011, 47, 182-191. [CrossRef] 
17. Morrongiello, B.A.; Lasenby-Lessard, J. Psychological determinants of risk taking by children: An integrative model and implications for interventions. Inj. Prev. J. Int. Soc. Child Adolesc. Inj. Prev. 2007, 13, 20-25. [CrossRef]

18. Thornton, S.; Pearson, A.; Andree, K.; Rodgers, N. Taking the child's perspective seriously. Psychologist 1999, 12, $393-394$.

19. Benjaminsen, C. How Attentive Are Children in Traffic? Available online: https://partner.sciencenorway.no/forskningnonorway-partner/how-attentive-are-children-in-traffic/14383312016 (accessed on 10 July 2021).

20. Connelly, M.L.; Conaglen, H.M.; Parsonson, B.S.; Isler, R.B. Child pedestrians' crossing gap thresholds. Accid. Anal. Prev. 1998, 30, 443-453. [CrossRef]

21. Scialfa, C.T.; Borkenhagen, D.; Lyon, J.; Deschênes, M.; Horswill, M.; Wetton, M. The effects of driving experience on responses to a static hazard perception test. Accid. Anal. Prev. 2012, 45, 47-553. [CrossRef] [PubMed]

22. Meir, A.; Oron-Gilad, T.; Parmet, Y. Can child-pedestrians' hazard perception skills be enhanced? Accid. Anal. Prev. 2015, 83, 101-110. [CrossRef]

23. Ellis, J. Bicycle Safety Education for Children from a Developmental and Learning Perspective; National Highway Traffic Safety Administration: Washington, DC, USA, 2014.

24. Trifunović, A.; Pešić, D.; Čičević, S.; Antić, B. The importance of spatial orientation and knowledge of traffic signs for children's traffic safety. Accid. Anal. Prev. 2017, 102, 81-92. [CrossRef]

25. Ivarsson, B.J.; Crandall, J.R.; Okamoto, M. Influence of age-related stature on the frequency of body region injury and overall injury severity in child pedestrian casualties. Traffic Inj. Prev. 2006, 7, 290-298. [CrossRef]

26. Olofsson, E. Children Injured in Traffic in a Medical and Psychosocial Perspective: Causes and Consequences; Sahlgrenska Academy, University of Gothenburg: Gothenburg, Sweden, 2014.

27. Lavie, N. Distracted and confused?: Selective attention under load. Trends Cogn. Sci. 2005, 9, 75-82.

28. Tabibi, Z.; Pfeffer, K. Finding a safe place to cross the road: The effect of distractors and the role of attention in children's identification of safe and dangerous road-crossing sites. Infant Child Dev. 2007, 16, 193-206. [CrossRef]

29. Hillier, L.M.; Morrongiello, B.A. Age and gender differences in school-age children's appraisals of injury risk. J. Pediatric Psychol. 1998, 23, 229-238. [CrossRef]

30. Hill, R.; Lewis, V.; Dunbar, G. Young children's concepts of danger. Br. J. Dev. Psychol. 2000, 18, 103-119. [CrossRef]

31. Schwebel, D.C.; Stavrinos, D.; Byington, K.W.; Davis, T.; O’Neal, E.E.; de Jong, D. Distraction and pedestrian safety: How talking on the phone, texting, and listening to music impact crossing the street. Accid. Anal. Prev. 2012, 45, 266-271. [CrossRef] [PubMed]

32. Tapiro, H.; Oron-Gilad, T.; Parmet, Y. Cell phone conversations and child pedestrian's crossing behavior; A simulator study. Saf. Sci. 2016, 89, 36-44. [CrossRef]

33. Thomson, J.; Tolmie, A.; Foot, H.C.; McLaren, B. Child Development and the Aims of Road Safety Education: A Review and Analysis; Road Safety Research Report No.1; HMSO: London, UK, 1996.

34. Morrongiello, B.A.; Barton, B.K. Child pedestrian safety: Parental supervision, modeling behaviors, and beliefs about child pedestrian competence. Accid. Anal. Prev. 2009, 41, 1040-1046. [CrossRef] [PubMed]

35. Simons, A.; Koekemoer, K.; Niekerk, A.V.; Govender, R. Parental supervision and discomfort with children walking to school in low-income communities in Cape Town, South Africa. Traffic Inj. Prev. 2018, 19, 391-398. [CrossRef] [PubMed]

36. Barton, B.K.; Schwebel, D.C. The roles of age, gender, inhibitory control, and parental supervision in children's pedestrian safety. J. Pediatr. Psychol. 2007, 32, 517-526. [CrossRef]

37. Granié, M.-A. Gender differences in preschool children's declared and behavioral compliance with pedestrian rules. Transp. Res. Part F Traffic Psychol. Behav. 2007, 10, 371-382. [CrossRef]

38. Wills, K.E.; Christoffel, K.K.; Lavigne, J.V.; Tanz, R.R.; Schofer, J.L.; Donovan, M.; Kalangis, K.; Kids 'N’Cars Research Team. Patterns and correlates of supervision in child pedestrian injury. J. Pediatric Psychol. 1997, 22, 89-104. [CrossRef] [PubMed]

39. Wills, K.E.; Tanz, R.R.; Christoffel, K.K.; Schofer, J.L.; Lavigne, J.V.; Donovan, M.; Kalangis, K. Supervision in childhood injury cases: A reliable taxonomy. Accid. Anal. Prev. 1997, 29, 133-137. [CrossRef]

40. Roberts, I.; Coggan, C. Blaming children for child pedestrian injuries. Soc. Sci. Med. 1994, 38, 749-753. [CrossRef]

41. MacGregor, C.; Smiley, A.; Dunk, W. Identifying gaps in child pedestrian safety: Comparing what children do with what parents teach. Transp. Res. Rec. 1999, 1674, 32-40. [CrossRef]

42. Harrison, A. Road Safety: Insurers Show Accidents Near Schools. 2013. Available online: https://www.bbc.com/news/ education-23899232 (accessed on 6 July 2021).

43. Ortigosa, J.; Gayah, V.V.; Menendez, M. Analysis of one-way and two-way street configurations on urban grid networks. Transp. B Transp. Dyn. 2019, 7, 61-81. [CrossRef]

44. Wazana, A.; Rynard, V.L.; Raina, P.; Krueger, P.; Chambers, L.W. Are child pedestrians at increased risk of injury on one-way compared to two-way streets? Can. J. Public Health 2000, 91, 201-206. [CrossRef] [PubMed]

45. Oxley, J.; Fildes, B.; Ihsen, E.; Charlton, J.; Day, R. Differences in traffic judgements between young and old adult pedestrians. Accid. Anal. Prev. 1997, 29, 839-847. [CrossRef]

46. Federal Highway Administration. Road Design: One-Way/Two-Way Street Conversions, in FHWA Safety; Federal Highway Administration: Washington, DC, USA, 2018.

47. Walker, G.W.; Kulash, W.M.; McHugh, B.J.T. Downtown Streets: Are We Strangling Ourselves in One-Way Networks; Transportation Research Board: Dallas, TX, USA, 2000.

48. David, N.K.-B. The role of the physical environment in child pedestrian accidents. J. Adv. Transp. 1994, 28, 171-187. [CrossRef] 
49. Apardian, B.; Alam, B.M. A study of effectiveness of midblock pedestrian crossings. Interdiscip. J. Signage Wayfinding 2017, 1, 26-59. [CrossRef]

50. Pawar, D.S.; Patil, G.R. Pedestrian temporal and spatial gap acceptance at mid-block street crossing in developing world. J. Saf. Res. 2015, 52, 39-46. [CrossRef]

51. Bhuiyan, N.F. Enhancing Pedestrian Safety in Bangladesh. Available online: https://www.researchgate.net/publication/332057 524_ENHANCING_PEDESTRIAN_SAFETY_IN_BANGLADESH (accessed on 6 July 2021).

52. Park, S.; Lim, J.; Kim, H.; Lee, S. Accidents involving Children in School Zones Study to identify the key influencing factors. Int. J. Highw. Eng. 2017, 19, 167-174. [CrossRef]

53. Leden, L.; Gårder, P.; Johansson, C. Safe pedestrian crossings for children and elderly. Accid. Anal. Prev. 2006, 38, 289-294. [CrossRef]

54. Johansson, C.; Leden, L. Short-term effects of countermeasures for improved safety and mobility at marked pedestrian crosswalks in Borås, Sweden. Accid. Anal. Prev. 2007, 39, 500-509. [CrossRef]

55. Van Haperen, W.; Riaz, M.S.; Daniels, S.; Saunier, N.; Brijs, T.; Wets, G. Observing the observation of (vulnerable) road user behaviour and traffic safety: A scoping review. Accid. Anal. Prev. 2019, 123, 211-221. [CrossRef]

56. Van Haperen, W.; Riaz, M.S.; Daniels, S.; Saunier, N.; Brijs, T.; Wets, G. Validity of instruments to assess students' travel and pedestrian safety. BMC Public Health 2010, 10, 257.

57. Lombard, M.; Snyder-Duch, J.; Bracken, C.C. Content analysis in mass communication: Assessment and reporting of intercoder reliability. Hum. Commun. Res. 2002, 28, 587-604. [CrossRef]

58. McHugh, M.L. Interrater reliability: The kappa statistic. Biochem. Med. 2012, 22, 276-282. [CrossRef]

59. Allison, P. Convergence failures in logistic regression. SAS Global Forum 2008, 360, 1-11.

60. Erke, A.; Elvik, R. Making Vision Zero Real: Preventing Pedestrian Accidents and Making Them Less Severe; Transportøkonomisk institutt: Oslo, Norway, 2007.

61. Wang, H.; Tan, D.; Schwebel, D.C.; Shi, L.; Miao, L. Effect of age on children's pedestrian behaviour: Results from an observational study. Transp. Res. Part F Traffic Psychol. Behav. 2018, 58, 556-565. [CrossRef]

62. Lesley, G. Enhancing the daytime conspicuity of pedestrians through the usage of fluorescent materials. Color Res. Appl. 1995, 20, 117-123. [CrossRef]

63. Zegeer, C.V.; Bushell, M. Pedestrian crash trends and potential countermeasures from around the world. Accid. Anal. Prev. 2012, 44, 3-11. [CrossRef]

64. Grayson, G.B. The identifiction of training objectives: What shall we tell the children? Accid. Anal. Prev. 1981, 13, 169-173. [CrossRef]

65. Van der Molen, H.H. Behavior of children and accompanying adults at a pedestrian crosswalk. J. Saf. Res. 1982, 13, 113-119. [CrossRef]

66. Makalew, F.P.; Adisasmita, S.A.; Wunas, S.; Hamid, S. Influence of children pedestrian behaviour on pedestrian space usage. IOP Conf. Ser. Mater. Sci. Eng. 2017, 271, 012028. [CrossRef]

67. Islam, S.; Jones, S.L. Pedestrian at-fault crashes on rural and urban roadways in Alabama. Accid. Anal. Prev. 2014, 72, 267-276. [CrossRef] [PubMed]

68. Riaz, M.S.; Cuenen, A.; Janssens, D.; Brijs, K.; Wets, G. Evaluation of a gamified e-learning platform to improve traffic safety among elementary school pupils in Belgium. Pers. Ubiquitous Comput. 2019, 23, 931-941. [CrossRef]

69. Fyhri, A.; Bjørnskau, T.; Ulleberg, P. Traffic education for children with a tabletop model. Transp. Res. Part F Traffic Psychol. Behav. 2004, 7, 197-207. [CrossRef]

70. Schwebel, D.C.; Barton, B.K.; Shen, J.; Wells, H.L.; Bogar, A.; Heath, G.; McCullough, D. Systematic review and meta-analysis of behavioral interventions to improve child pedestrian safety. J. Pediatr. Psychol. 2014, 39, 826-845. [CrossRef]

71. Wegman, F.; Aarts, L.; Bax, C. Advancing sustainable safety: National road safety outlook for The Netherlands for 2005-2020. Saf. Sci. 2008, 46, 323-343. [CrossRef]

72. Ben-Bassat, T.; Avnieli, S. The effect of a road safety educational program for kindergarten children on their parents' behavior and knowledge. Accid. Anal. Prev. 2016, 95, 78-85. [CrossRef]

73. Schwebel, D.C.; Combs, T.; Rodriguez, D.; Severson, J.; Sisiopiku, V. Community-based pedestrian safety training in virtual reality: A pragmatic trial. Accid. Anal. Prev. 2016, 86, 9-15. [CrossRef]

74. Federal Highway Administration. Raised Crosswalk, in Safe Transportation for Every Pedestrian: Countermeasure Tech Sheet; Federal Highway AdministrationFederal Highway Administration: Washington, DC, USA, 2018. 